\title{
A Comparison of the Public Realm in CBDs in Shenzhen
}

\author{
Yiyong Chen \\ College of Architecture and Urban plan, \\ Shenzhen University \\ Shenzhen, China \\ chenyiy@szu.edu.cn
}

\author{
John Zacharias \\ College of Architecture and Landscape, \\ Peking University \\ Beijing, China \\ johnzacharias@pku.edu.cn
}

\begin{abstract}
-
Objective: This paper tracked the emergence process of three CBDs in Shenzhen, and made a comparison of the public realm among them.

Methods: Field investigation was conducted over the public realm in the three CBDs, including land use, parking, motor $\&$ non-motor traffic and public space.

Results: Luohu CBD grew spontaneously out of the old city center. The CBD looks vital and crowded: Life is convenient here but the crowded environment seems not suited for business. The latter "elaborately planned" two CBDs made a lot of revisions. However, in Futian CBD, the huge size Axis Park and the wide Shennan Road became an obstacle for non-motor traffic. The generation 3 CBD Qianhai is mostly under construction.

Conclusion: The challenges that Luohu faces are the crowded spaces, heavy traffic, insufficient parking spaces and shortage of public spaces. Its development mode should transfer from horizontal to vertical. The Futian CBD is better for motor traffic, but the cycling and pedestrian system never forms a convenient traffic system among the business buildings inside the CBD. The urban design of the earlier two CBDs also provides lot of inspiration and lessons for the public realm for Qianhai.
\end{abstract}

Keywords- public realm; comparison; Luohu; Futian; Qianhai-Houhai; Shenzhen

\section{INTRODUCTION}

Shenzhen, the fourth biggest city in China, is also one of its youngest cities. Although with a short history, its development has been rapid and became an unparalleled precedent in city development history in China. The fast growth of Shenzhen started from 1979 with China's Reform and Opening up. Later Shenzhen Special Economic Zone (SEZ), the first in China, was set up. The population of Shenzhen expanded rapidly, from 30 thousand in 1980 to 1 million in 1986, and 10 million in 2005. In several decades, urbanization has transformed the area from a small fishing village into one of China's most modernized cities[1]. Commercial and business areas are formed in strategic locations within SEZ, and they perform important economic functions within the Pearl River Delta Region[2].

With the fast expansion of built-up area of the city, a multi-centered linear city formed. As China's communication window with the Asian financial center Hong Kong, the financial industry quickly became prosperous in Shenzhen. There appeared several so-called CBDs in the past years, e.g. Luohu old CBD, Futian new CBD, and Qianhai-Houhai western CBD. All of them have close economic and geographical links with Hong Kong[3]. All of these CBDs had served or presumed to be serving as financial center of the city, or of an even bigger area.

This paper tries to illustrate the growth process of the three CBDs, and makes a comparison of the three CBDs, in the domain of urban design concept, traffic system and public space.

\section{THE EMERGENCE OF 3 CBDS}

\section{A. The initial urban center: Luohu}

The development of Luohu CBD, as well as modern Shenzhen city, started from the Luohu port of entry. At the initial period, the development of Shenzhen relied on favorable economic policies and overseas investments. Luohu district at the border between Mainland China and Hong Kong became a logical choice for location of the initial urban center. Convenient transport accessibility is another key feature of this area, which is located right next to the port and well served by railway.

In the 1990s, with the setup of Shenzhen Stock Exchange Center, one of only two stock exchange centers in China, Shenzhen's financial industry began its fastgrowth period. Luohu quickly became the financial and business center of Shenzhen. The whole development enabled the concentration of commercial, financial, business and tourist activities.

According to a construction census in 2000, compared with Futian and Nanshan District, Luohu had both the most commercial buildings and the most business buildings. 9.92\% of the gross floor area in Luohu District was commercial buildings, which were mainly concentrated in the CBD. $14.05 \%$ of the gross floor area in Luohu was in business buildings, which mainly concentrated in Caiwuwei and Guomao areas.

However, according to a series of reasons, Luohu turned out to be a temporary CBD for the following reasons:

- Luohu is located at one corner of the belt city, far away from the geometric center of Shenzhen,

- Luohu is far away from the Guangzhou-Hong Kong economic corridor, the main economic growth direction of Shenzhen, 
- In the 1990s, the commercial center and business center of Shenzhen was gradually on its way westward. New regional centers prospered, like Huaqiangbei, Shangbu, Xiasha, et al [4].

- $\quad$ Luohu is too confined to meet the fast growth of population and economic demand in Shenzhen.

Not surprisingly, the new urban center and the new CBD were already on their way to surpassing Luohu.

\section{B. The transfer from Luohu to Futian}

In the 1990s, especially after Deng's "Southern Tour", Shenzhen experienced a fast growing period. The business space demand was still increasing. The time was ripe for the launch of a new urban center, to meet the demand of a super city populated by over 10 million.

Futian was a perfect option. It located at the center of the belt city, convenient to reach every other district of Shenzhen. The opening of Futian port and Huanggang port made Futian easy for communications with Hong Kong.

Futian CBD is divided by Shennan Avenue into two parts. The northern part is mainly the administrative and cultural center with a total area of 180ha, where a lot of important public buildings gathered. The southern part is mainly the financial center with a total area of 233ha, mainly official buildings, as well as the Convention and Exhibition Centre and several up-scale hotels.

The 1986 Master Plan had selected the site of the Futian urban center and established its basic concept. In 1992, the detailed plan and traffic plan of Futian urban center were submitted to the municipal government followed by the construction of major roads and secondary streets. The massive construction of business buildings mainly came after the 1998 Asia financial crisis, and achieved its peak between 2004 and 2008. By the end of 2012, the gross constructed area of Futian CBD was $8.2 \mathrm{million} \mathrm{m}^{2}$, of which 3.7 million was for business. Another 2.1 million $\mathrm{m}^{2}$ is still under construction, which is mostly for business [5].

\section{Manhattan dream: Qianhai CBD}

Qianhai, the 15 square kilometer coastal strip in Nanshan district, has been dubbed "Manhattan of the Pearl River Delta", and largely perceived to be the generation $3 \mathrm{CBD}$ in Shenzhen. In "the master plan of Shenzhen city (2010-2020)", the Qianhai center was planned to be the new one of the double city centers in Shenzhen, which consisted of Qianhai, Houhai (Nanshan urban center) and the center area of Bao'an, compared with Futian-Luohu old city center.

The government hopes that Qianhai will become an economic center of Pearl River Delta, which connects more closely Shenzhen with Hong Kong and Guangzhou. Qianhai is located in the west of Nanshan District, about $15 \mathrm{~km}$ from Futian CBD. This seems not an attractive location, but with the construction of new transportation infrastructure, Qianhai will become a regional transportation center. What is more, Qianhai located in the middle of the Guangzhou-Shenzhen-Hong Kong economic corridor.

According to Shenzhen master plan, Qianhai and Houhai will be bound together to serve as the western urban center of Shenzhen. Houhai is located on the corner of Shenzhen Bay, next to the Shenzhenwan control point between Hong Kong and Shenzhen. Its central area could be divided into two areas, Nanshan business center in the east, and Nanshan commercial and cultural center in the west. With the continued westward movement of the city center of Shenzhen, Houhai has become an important carrier of the western central area.

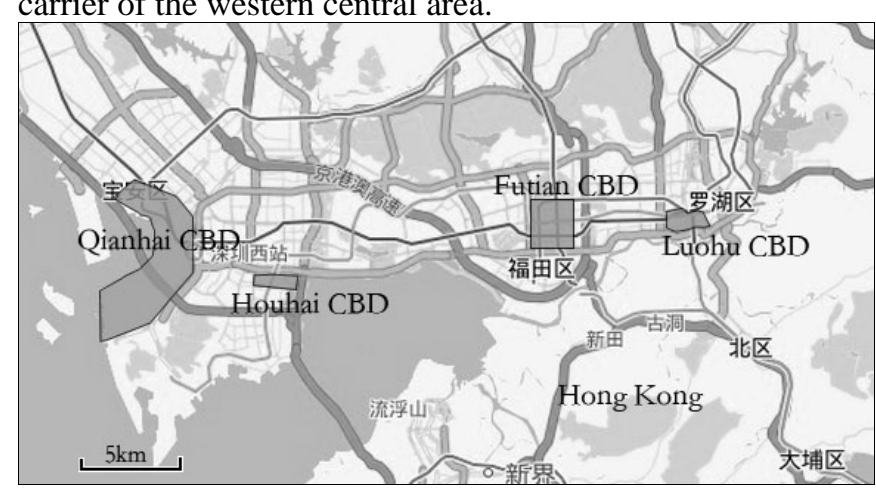

Figure 1. Location of the CBDs in Shenzhen

Note: Qianhai and Houhai together formulated the Western CBD

\section{A COMPARISON OF THE PUBLIC REALM}

\section{A. A comparison of the general plan of 3} CBDs

1) Luohu: spontaneous growth

At the beginning, Luohu was not expected to be so large. In 1980, the population of Bao'an old town, the predecessor of Shenzhen, was no more than 30 000. But in 1986, the urban population of the city surpassed 1 million. Then in 2005, the population broke through 10 million. With the city's fast-growing process, the urban plan and urban form of Luohu changed rapidly.

It is difficult to define the boundary of Luohu CBD. Taking the zoning of Luohu master plan for reference, we try to use Dongmen South Road, Yanhe Road, Binhe Road, Hongling Road and Shennan Road as a boundary, where most of the business buildings in Luohu gathered. However, the two tallest skyscrapers, Diwang and Kingkey 100 were excluded. So several northern plots should be added, used mainly for business, developed a little later. The total land area is 211.2ha.

\section{2) Mixed land use in Luohu}

The land use of Luohu CBD is fully mixed. Almost every plot has two or three different uses. Neither residential land nor business land accumulate in clear areas, but remain intermixed. According to the statistic of our field investigation, $18.9 \%$ of land area is used for business, $10.0 \%$ for commercial and $31.4 \%$ for residential. The financial and business buildings mainly concentrated along the Shennan Road and Renminnan Road. It seems strange in retrospect that the south area adjacent the control point are mainly residential buildings. There are even several urban villages inside this area, like the Luohu village to the north of the control point, and the Caiwuwei village to the south of Shenzhen Stock Exchange Center.

Although it grew gradually over the last 30 years, the development intensity of Luohu CBD is high. The gross plot ratio of the whole area is 3.19 in 2013. Several urban villages are being renewed; more business buildings will be added. To certain plots, the FAR could be higher. The gross building coverage of the area is $26.3 \%$. 


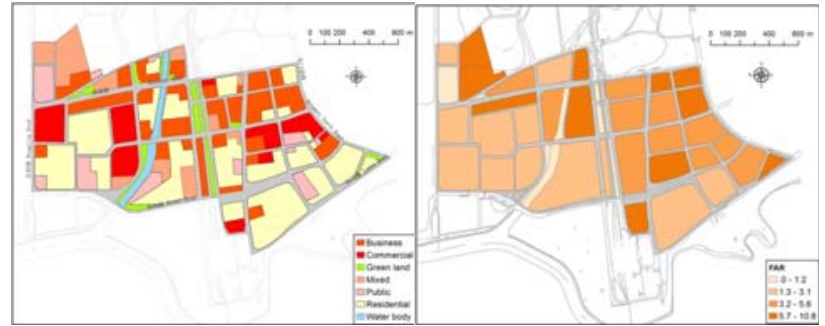

Figure 2. Land exploit of Luohu CBD: land use and FAR by plots

\section{3) Simplex land use in Futian}

Compared with Luohu, Futian CBD was elaborately planned. It is located at the center of Shenzhen city, traversed by the west-east axis Shennan Road. Its boundary was explicit, e.g. Binhe Avenue, Caitian Road, Hongli Road, and Xinzhou Road, covered an area of 414 ha. Dozens of skyscrapers accumulated here, especially in the south of Shennan Road, along both sides of Fuhua Road and Shennan Road.

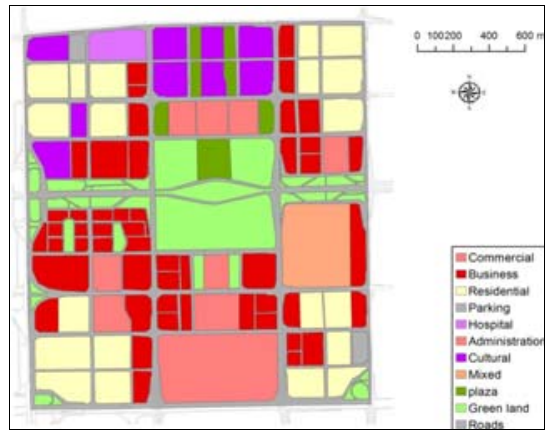

Figure 3. Land use of Futian CBD

The land use division was also explicit. Almost every block has a simplex land use type. The proportion of land area for business is $19.0 \%$, which is highest among all land use types. The proportion for commercial is $9.8 \%$, in which there is a super large plot for the Convention and Exhibition Center, with a total area of 25.5 ha. Green space and public space accounted for $16.1 \%$, which is fairly high compared with other CBDs. In the middle of the whole area is a $600 \mathrm{~m}$ by $600 \mathrm{~m}$ green land, divided by Shennan Road into several parks. The residential land situated in four corners of the CBD, developed around 1998 before other plots.

4) Complex development land in Qianhai

The urban form of Qianhai is bound together with Bao'an center area, which is located to the north. The two centers formed a half-circle surrounding the Qianhai Bay. Thus Qianhai will be formed by several cambered paralleled long belts: from coastal line to the inland is the cultural and coastal green belt, the wide business belt, the residential belt. The whole area of Qianhai will be divided by two rivers into three sub-areas: Guiwan, Mawan and Chanwan, each given different functions. Guiwan area is supposed to be the core business area.

TABLE 1. A comparison of the urban form of 3 CBDs

\begin{tabular}{llll}
\hline Item & Luohu & Futian & Qianhai \\
\hline Land area/ha & 211.2 & 414.0 & 1492 \\
FAR & 3.19 & 2.49 & 1.74 \\
Building coverage & $26.3 \%$ & $22.3 \%$ & - \\
Gross floor area /million sq m & 6.74 & 10.30 & 26.0 \\
Business floor area /million sq m & 2.99 & 5.80 & 16.0 \\
Residential floor area /million sq m & 2.26 & 2.42 & 3.8 \\
Average block area /ha & 6.03 & 4.6 & - \\
\hline
\end{tabular}

Land use of each plot was not assigned like other plans, but named by several kinds of complex development land in the master plan. So, different functions, including commercial, business, cultural, administrative, service, etc., are supposed to be of all kinds of mixes inside Qianhai.

\section{B. Ground and underground traffic system}

Owing to different develop modes, the traffic systems in 3 CBDs are of great difference. In Luohu CBD, conventional ground transportation was the major traffic form. There were only two metro lines crossing this area until now, with 4 stations, around which concentrated many business buildings. Another metro line, line 9, which passes by the south and west edge, is under construction. Only one expressway passes by Luohu CBD, namely Binhe Road, which is always in a traffic jam. Furthermore, the adjacent Luohu immigration point and Luohu railway station attract high traffic flow, both public and private, which makes the traffic in Luohu always crowded. In the beginning, the traffic system made Luohu CBD, but later the traffic system did not improve and damaged further CBD development.

In Futian CBD, the underground rail system played a more important role. Four metro lines cross this area, with 8 stations, forming a grid network. Several others are under construction, including the Guangzhou-Hong Kong high-speed rail, the airport express rail, which helps Futian become a convenient traffic junction. To enhance the earlier development of CBD, Metro Line 1 even changed its original path to pass through the center of the southern plots of Futian [6].

The grid road network makes motor traffic in Futian fast and convenient. The main roads are mostly expressway, broad with few intersections. The branch roads are also wide with no cul-de-sacs in the system except for access into public-utility facilities and parking garages. Especially, from the south to the north, when crossing the Shennan Road, four overpasses were built, comparing with four level intersections on Shennan Road in Luohu CBD.

In Qianhai, the underground traffic routes are even denser. There will be 12 metro lines or light railways passing by, with a total metro line length of 53 kilometers. The ground road density in Qianhai is also planned to be higher than that in Luohu and Futian. The expressway and main stem roads will connect the three sub-areas in Qianhai with the outside traffic system.

From the comparison, it is noticed that, in the latter two CBDs, the underground use for traffic is much more intense than the earlier one. Public transportation plays a more important role, especially in Qianhai. At the same time, the ground expressway system in the latter two CBDs is also advanced.

TABLE 2.A comparison of the traffic system

\begin{tabular}{llll}
\hline Item & Luohu & Futian & Qianhai \\
\hline Road length & $22.23 \mathrm{~km}$ & $41.26 \mathrm{~km}$ & $180 \mathrm{~km}$ \\
Road density $/ \mathrm{km} / \mathrm{km}^{2}$ & 10.5 & 10.8 & 12.1 \\
Metro stations & 6 & 9 & - \\
Metro length & $8.3 \mathrm{~km}$ & $13.7 \mathrm{~km}$ & $53 \mathrm{~km}$ \\
Metro lines & 3 lines & $6 l i n e s$ & 12 lines \\
Bus stops & 19 & 36 & - \\
Average traffic flow & 1975 motors $/ \mathrm{h}$ & 931 motors $/ \mathrm{h}$ & - \\
\hline
\end{tabular}




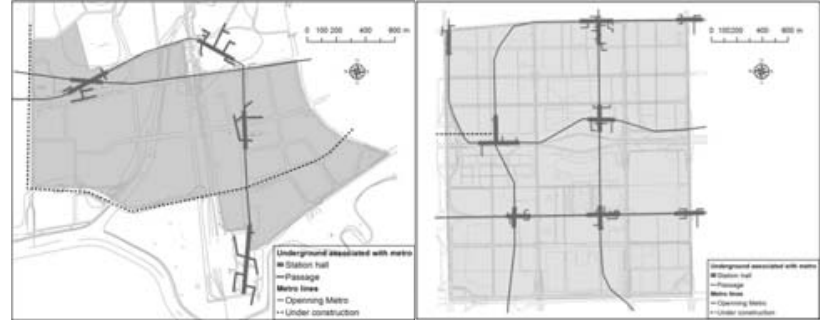

Figure 4. Comparison of the metro system in Futian \& Luohu

Parking greatly affects the running of the traffic system in the CBD, especially the use of private car. The parking space supply and use in different CBDs is diverse. The total parking space supply in Luohu CBD is 14 thousand, $40 \%$ of which is ground-level parking. This takes up a great part of the limited ground space, if calculated by 30 sq meters one parking space, the total land area for ground-level parking is 16.8ha, accounting for $8.0 \%$ of the whole area of the CBD. However, because of insufficient underground parking space, the illegal parking in Luohu is severe, accounting for $13.9 \%$ during the weekdays, $15.2 \%$ during the weekend, compared with $6.2 \%$ of weekdays and $6.1 \%$ of weekends in Futian.

TABLE 3. A comparison of the car parking

\begin{tabular}{lllll}
\hline Item & Luohu & Futian & Houhai \\
\hline Ground-level parking spaces & 5609 & 4204 & 0 \\
Underground parking spaces & 8368 & 28281 & 3152 \\
Weekdays & Ground-level parking & 4269 & 2954 & 0 \\
& Illegal parking & 1620 & 1544 & 244 \\
\multirow{4}{*}{ Weekend } & Underground parking & 5765 & 20478 & 1690 \\
& Ground-level parking & 4594 & 1890 & 0 \\
& Illegal parking & 1912 & 1145 & 365 \\
& Underground parking & 6092 & 15455 & 1820 \\
\hline
\end{tabular}

The average parking space supply in Futian CBD, compared with Luohu, increased by $20 \%$ to 79 spaces per ha, and $87.1 \%$ of which is underground parking spaces. At the same time, because of the proper use of the underground space, the land used for parking spaces decreased dramatically.

In the generation $3 \mathrm{CBD}$, ground parking spaces will be even less: in Houhai, the ground parking space supply is strictly limited. Less ground parking spaces, more open space and green land. The parking comparison may help explain the perception of crowdedness and little public space in Luohu.

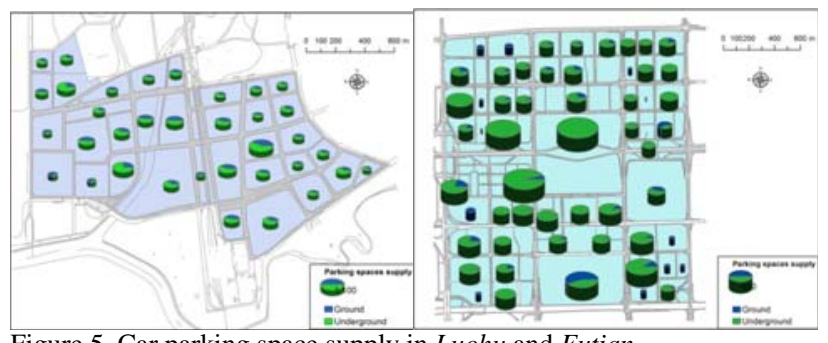

Figure 5. Car parking space supply in Luohu and Futian

\section{Non-motorized traffic system}

The non-motorized traffic system is greatly influenced by the road system. In Luohu, the cycling lanes and sidewalks are fluent and seldom interrupted by overpasses or broad blocks, making walking and cycling convenient. In Futian, the cycling and walking system are greatly affected by the fast motor traffic, resulting in a much smaller cyclist and pedestrian flow than that in Luohu, especially the cross Shennan Road flow. At the same time, the Shennan Road and its green belt, about 300 meters wide, made the north to south non-motor traffic even more difficult. However, the financial buildings in the south will need frequent connections with the new stock exchange center and the municipal hall located in the north. To facilitate the north to south pedestrian traffic, a 250-meters-wide central axis was planned which, did not reach its destination, but even made the east-west pedestrian traffic more difficult. So the cycling and walking environment in Futian area is disastrous.

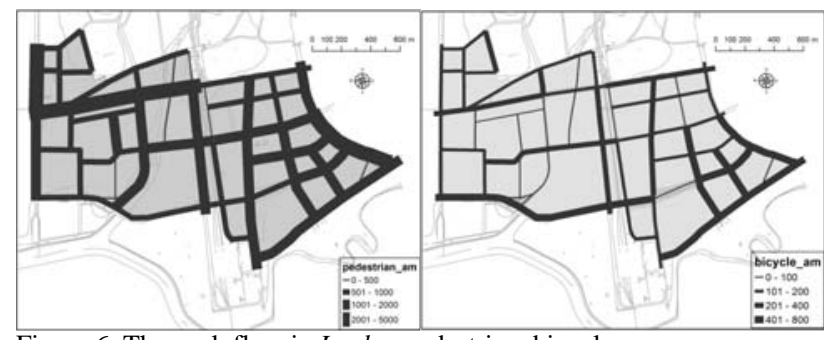

Figure 6. The peak flow in Luohu: pedestrian, bicycle

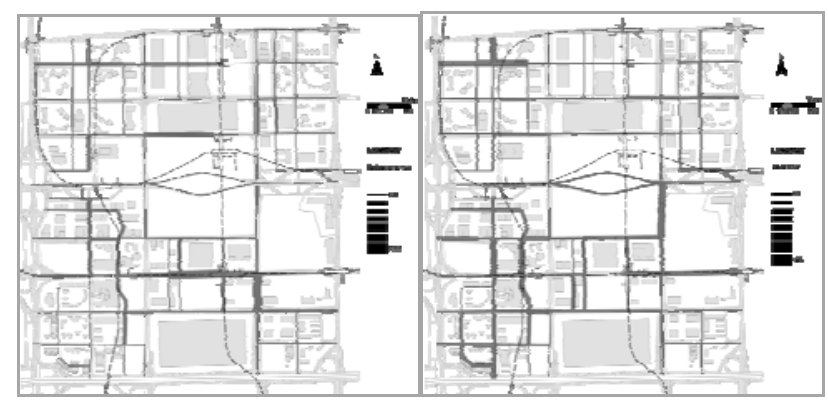

Figure 7. The peak flow in Futian: pedestrian, bicycle

In Qianhai, according to its master plan, the nonmotor traffic system seems more rational. The whole area was divided into three sub-areas, with relatively independent functions. So every group could easily get into the expressway, and the inner non-motor traffic will not be interrupted by the expressway.

In a word, the non-motor traffic system in Luohu and Qianhai CBD is convenient. But compared with Luohu $\mathrm{CBD}$, the traffic system in Futian CBD made certain progress in motor traffic, at the cost of inconvenient cycling and walking system. The external effect brought by agglomeration of business buildings in CBD, which makes white collar workers from adjacent buildings establish easy face-to-face communication, was weakened to some extent. The fusion of financial center with political and cultural center failed in the sense of nonmotor traffic system in Futian.

The bicycle use in Luohu is much more frequent than that in Futian, which could be observed from the average bicycle flow in main roads and bicycle parking. The average peak flow of bicycles in main roads of Luohu is almost twice more than that in Futian. However, both in Luohu and Futian, bicycle users concentrated in the residential blocks, while in the business blocks bicycle use is much less.

The bicycle facilities, including the parking space supply and bicycle lanes, greatly affect the bicycle uses [7]. In Luohu, the cyclist could easily ride a bike on the 
main roads, as well as the branch roads, on the bicycle lanes, which are distributed on most of both sides of the main roads, forming a bicycle lane network. Almost every block assigned special land for bicycle parking.

But in Futian, the public facilities are not so friendly to cyclists. The bicycle lanes are distributed only on the outlying main roads and certain roads of the south parts. On other roads, cyclists should ride on the sidewalks or the motorway. The various overpasses and expressways are also great obstacles for cyclists. Only a quarter of all the blocks assigned special land for bicycle parking. The total bicycle parking space supply per hectare is only $30 \%$ of that in Luohu.

From the comparison of the bicycle uses and facilities in the earlier two CBDs, we could see an almost opposite attitude towards bicycle use. Luohu was mostly a bicycle friendly CBD in urban design, so the bicycle uses are frequent and convenient. In Futian, the bicycle facilities, including both the bicycle lanes and parking, are not so perfect, resulting in much less bicycle use.

For the generation $3 \mathrm{CBD}$, the bicycle use seems to have received special attention. In Qianhai CBD, a total length of $36.8 \mathrm{~km}$ bicycle lane was planned, which consists of lanes for metro transfer and for leisure activities. Land was also assigned for bicycle parking around some metro stations. In Houhai CBD, we have already seen frequent bicycle uses throw bicycle flow and parking.

TABLE 4.A comparison of the Bicycle parking \& uses

\begin{tabular}{llll}
\hline Item & Luohu & Futian & Houhai \\
\hline Parking spaces & 4154 & 2455 & 858 \\
Weekdays ground parking & 2837 & 1704 & 833 \\
Weekdays illegal parking & 1099 & 302 & 453 \\
Weekend ground parking & 2665 & 819 & 718 \\
Weekend illegal parking & 1016 & 193 & 526 \\
Length of bicycle lanes & $20.0 \mathrm{~km}$ & $16.6 \mathrm{~km}$ & - \\
Average traffic flow & 243 & 85 & - \\
\hline
\end{tabular}

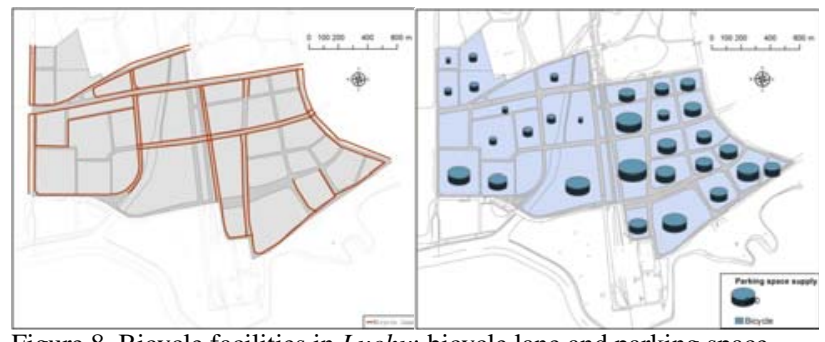

Figure 8. Bicycle facilities in Luohu: bicycle lane and parking space

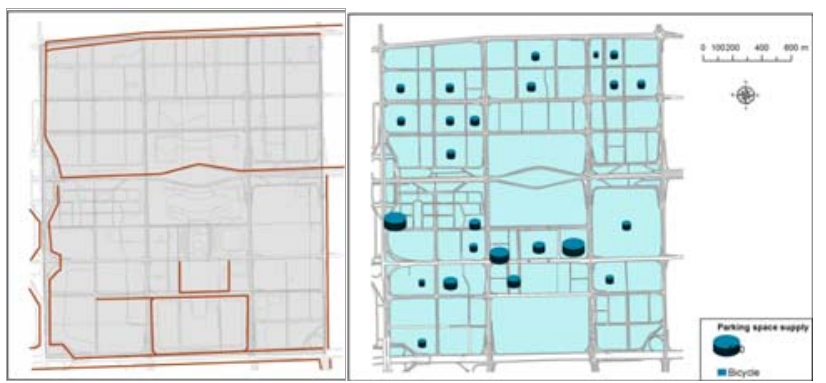

Figure 9. Bicycle facilities in Futian: bicycle lane and parking space

\section{Size and distribution of public spaces}

Public space is one of the two most important urban design elements in CBD, while the other is the traffic system as discussed above. The distribution of public spaces and their uses in different generation CBDs are diversity. In Luohu, there was not much space assigned for public uses. The public spaces are composed mainly by pocket gardens, street green lands, community parks, and small squares, concentrated in Guomao area and both sides of Shennan Road. The size of every park is fairly small, the largest of which is no more than 2ha. However, most of them are frequently visited by the citizens. The total area of the 21 little parks and squares is 11.48ha, accounting for $5.4 \%$ of the land area. Public space is a kind of scarce resource here, but used intensively.

In Futian, the land for green space and public space is 54.7ha, accounting for $16.1 \%$ of the total land area, much more than Luohu. 19.7 ha of that area is roadside green land. The Axis Park in the center of Futian CBD, from Lotus Hill Park to the South Axis Park, is almost 2000m long and 250m wide, occupied mostly by public space, however attracting few visitors [8]. The center plaza especially, $600 \mathrm{~m}$ by $600 \mathrm{~m}$, separated by Shennan road into three parts, was the biggest public space but attracts the least visitors. Those public spaces visited frequently by the CBD white collars, were the small parks scattered among the business blocks, like the two parks in the southwest connected by Road No.2.

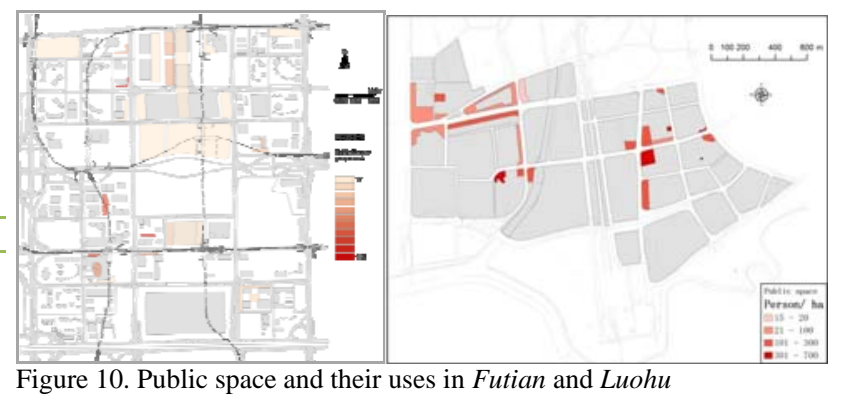

In the CBD, the small size public spaces are more attractive. They are easy to reach, convenient to use, and frequently used. The large scale public spaces not only take up huge land area, but also always are not convenient to reach. From an overall view, the large scale parks are mostly theme parks, like sports parks, plants parks, and recreational parks. Few located inside the CBD whose land rent is relatively high.

The public space in generation $3 \mathrm{CBD}$ seems to be more rational and attractive. According to the Qianhai master plan, the public spaces will be comprised of small parks, slit long green belts and several waterfront recreational corridors, which served as the boundary of three sub-areas. The green belts, about 30 to 50 meters wide, cross and connect the blocks. In Houhai, the public spaces consist of two small parks on the edge of the area, and a small square in the middle, which are also small and always intensively used.

\section{DISCUSSION AND CONCLUSION}

With the fast growth of China's economy, Shenzhen also undergoes a fast growth period, especially for its financial economy [9]. With the westward development of the city, the urban center of this coastal belt city transferred from Luohu in the east corner to Futian in the middle of the city. In the future, Qianhai is planned to be the western center. With the development of the financial 
economy, three CBDs emerged at different development periods of Shenzhen.

Luohu CBD, grew spontaneously out of the old city center, and is a traditional and vital downtown. Life is convenient here, especially for non-motor traffic. The CBD looks fairly crowded: narrow streets, high building density, high intensity and mixed land use, but this crowded environment is sometimes not suited for business. The challenges that Luohu faces are the crowded spaces, the crowded traffic, insufficient parking spaces, and insufficient public spaces. In the urban design of Luohu, the underground and overhead spaces should be considered. The development mode should transfer from horizontal to vertical.

The latter "elaborately planned" two CBDs made a lot of revisions: grid road network, express traffic system, lower building density, and much more open space. Although the FAR of the central area increased, the building density decreased. The average plot area is also decreasing. With high roads density, the CBD is better for traffic.

However, in Futian CBD, the huge-size Axis park and wide Shennan Road divide the whole business center into four parts, which made non-motor traffic difficult. What is more, the park is too big for pedestrians to cross conveniently. It is a motor-friendly, but non-motor inconvenient CBD. Life vitality is also absent here, especially in the northern part. So, one of the biggest challenges of Futian lies in the cycling and pedestrian system, which should form a convenient traffic system among the business buildings inside the CBD [10]. In Qianhai and Houhai, the underground and ground spaces, the motor and non-motor traffic, the public spaces, are more elaborately planned. The size of the space and block turns out to be suitable for motorized traffic, pedestrians and cyclists. To what extent they could be carried out remains to be seen.

$$
\text { Sponsored by NSFC(No.51408367) }
$$

\section{REFERENCES:}

[1] W.Chen, and C. Jim. Amenities and disamenities: a hedonic analysis of the heterogeneous urban landscape in Shenzhen. The Geographical Journal, 176, 2010, (3): 227-240.

[2] J. Zacharias and Y. Tang. Restructuring and repositioning Shenzhen, China's new mega city. Progress in Planning, 73, 2010: 209-249, doi:10.1016/j.progress.2010.01.002

[3] T. Chan and S. Zhao. Advanced producer services industries in Hong Kong and Shenzhen: struggles toward integration. Asia Pacific Viewpoint, 53,2012,(1): 70-85.

[4] J. Jiang. Space evolvement of Shenzhen urban central district. Urbanism and Architecture, 2005, (5):22-25

[5] Chen Yixin. The development of Shenzhen urban center, Library of Shenzhen University, 2013

[6] SPLRU(Shenzhen planning and land Resource Bureau). The international urban design consultation for core areas of Shenzhen central district. Beijing: China Architecture \& Building Press, 2002: 13-20.

[7] J.Zacharias. Generating urban lifestyle: The case of Hong Kong New-Town design and local travel behaviour. Journal of Urban Design, 10,2005, (3): 371-386.

[8] F. He and F. Ye. Creating a "Living Museum" in the Shenzhen CBD--The Master Planning Concepts of Lotus Hill Park. Journal of Chinese Landscape Architecture, 2003, (5):4-13.

[9] Y. Chen. CBD: urban design theories and cases. Beijing: China Architecture \& Building Press, 2006: 39-42.

[10] $\mathrm{T}$. Wong. The changing role of the central business district in the digital era: the future of Singapore's new financial district. Land Use Policy, 2004,(21):33-44. 